\title{
SLIDING WEAR BEHAVIOR OF AITIN PVD COATING ON TITANIUM ALLOY FOR ORTHOPEDIC APPLICATIONS
}

\author{
KIRUBEL AMSALU ${ }^{1}$, SIVAPRAKASAM. P $^{2 *}$, ELIAS $\mathbf{G}^{3} \&$ SARAVANAN M P $^{4}$ \\ ${ }^{1,2,3}$ Department of Mechanical Engineering, College of Electrical and Mechanical Engineering, Addis Ababa Science and \\ Technology University, Addis Ababa, Ethiopia \\ ${ }^{4}$ Department of Mechanical Engineering, Mohamed Sathak A J Engineering College, Chennai- 603103
}

\begin{abstract}
The present study focused on to investigate the tribological behavior of AlTiN coating on titanium alloy-(Ti-6Al-4V) through physical vapor deposition (PVD) for orthopedic applications. The sliding wear properties of coated samples were performed by pin on disc apparatus with ambient temperature. EN 31 alloy steel was chosen for counter materials as a pin with $6 \mathrm{~mm}$ diameter. RSM based design of experiments are carried out with three factors with three levels such as normal forces $(15,30$ and $45 \mathrm{~N})$; sliding speeds $(0.5,1$ and $1.5 \mathrm{~m} / \mathrm{s})$; and sliding distance $(500,1000$ and $1500 \mathrm{~m})$. The test was conducted at twenty different experimental combinations at randomly. The value of the wear mass loss was considered as response parameter. The minimal wear mass loss was found at applied load $15 \mathrm{~N}$, sliding speed $0.5 \mathrm{~m} / \mathrm{s}$ and sliding distance $500 \mathrm{~m}$.
\end{abstract}

KEYWORDS: RSM,ANOVA, Titanium Alloy, PVD, AlTiN

Received: Jun 09, 2020; Accepted: Jun 29, 2020; Published: Aug 03, 2020; Paper Id.: IJMPERDJUN2020589

\section{INTRODUCTION}

Titanium and its alloys have been extensively used for the various sectors like power generation, marine, medical and aerospace industries. It has high specific strength, excellent corrosion resistance with biocompatibility [1, 2]. Especially titanium alloy (Ti-6Al-4V) applied in load bearing bio-implants application. However, due to low surface hardness and poor tribological properties makes the limited to various applications [3].The abrasive wear has been one of the frequent causes of biomaterials damages [4]. This could lead to reduce the life of implant and also required for necessary treatments. The mechanical properties of components reduced by abrasive wear, which is contact of a tribological pair. In addition, they intensify pain and negative biological response of tissues which leads to local irritation and inflammation and consequently, to implant failure [5-7]. This has sufficient inert content for body fluids, fibroblast integration and osseointegration [8]. The tribological performance and surface characterization can be enhanced by TiN coating due to biocompatibility, high hardness and elastic modulus [9, 10]. It is also widely applied in decorative purpose, integrated circuits (IC), contact lenses, electronic circuits and devices [11].

The physical vapor deposition (PVD) techniques widely used many industrial applications because of many advantages such as resistance to corrosion, impact strength, excellent chemical and thermal stability and good surface integrity $[12,13]$. It is widely used for depositing wear-resistant thin film coatings [TiN, AlTiN, TiAlN] on various applications. The AlTiN coatings are widely applied due to numerous advantages including high hardness and wear resistance [14].The multilayer coating (AlTiN and $\mathrm{CrN}$ ) has significant improvements in mechanical 
properties, tribological properties, and oxidation and corrosion resistance [15, 16]. TiAlN coatings can significantly improve wear resistance in high temperature application due to $\mathrm{Al}$ in TiAlN coatings forms a superficial layer of composite ceramic [17]. The AlTiN hard coatings are widely applied as productive coating due to better tribological properties and high-temperature oxidation resistance [18-22].The coefficient of friction $(\mathrm{CoF})$ increases as load increases, where ascoatings decreases the CoF. Hence, it was concluded as AlTiN coatings are suitable cutting tools operating under heavy load at higher temperatures. [23].M.Szala, et.al [24] investigated the sliding wear mechanism of PVD coated stainless steel substrate (grade AISI 304).The results showed that AlTiN coated samples exhibited 24 times sliding wear resistance and two times decrease in friction coefficient than the uncoated substrates. Furthermore, it was observed that grooving, microscratching, micro-ploughing and smearing are the main types of sliding wear mechanisms.

In this study investigating the sliding wear behavior fan AlTiN coating deposited on titanium alloy using an arc evaporation method (PVD).The tribological properties are examined by pin-on-disc testing, preceded by wear track analysis using different analytical methods to understand the wear mechanisms, in particular wear mass loss. The effects of input parameters on wear test were analyzed by analysis of variance (ANOVA).

\section{MATERIALS AND METHOD}

\section{Materials}

The substrate material was considered for wear test has titanium alloy with a diameter of 50mm and a thickness of $10 \mathrm{~mm}$. The chemical composition of titanium alloy was shown in Table1. Ti6Al4V disks were mechanically grained and polished with required standard. AlTiN coatings were deposited by arc evaporation method using commercial Oerlikon Balzers coating system, India. The layer thickness of coating (AlTiN) was approximately $2 \mu$ m. Throughout the wear tests, the EN31 steel pin was chosen as counter-face material of $6 \mathrm{~mm}$ diameter and length $35 \mathrm{~mm}$ against the AlTiN coated Titanium alloy disk.

Table 1: Chemical Composition of Substrate Material (Ti6Al4V)

\begin{tabular}{|l|c|c|c|c|c|c|c|c|}
\hline Elements & $\mathbf{C}$ & $\mathbf{N}$ & $\mathbf{O}$ & $\mathbf{H}$ & $\mathbf{F e}$ & $\mathbf{V}$ & $\mathbf{A l}$ & $\mathbf{T i}$ \\
\hline Weight (\%) & 0.1 & 0.05 & 0.2 & 0.015 & 0.3 & $3.5-4.5$ & $5.5-6.75$ & Balance \\
\hline
\end{tabular}

\section{Design of Experiments-Response Surface Methodology (RSM)}

RSM is a statistical and mathematical technique that focuses on a few experiments that helps to develop, improve and optimize process parameters [25].It is widely used for engineering problem, especially to study the characterization of wear [26] and to predict and optimize a given model [27]. The developed model used for predicting the response value through approximating relationship between the response and the process variables. The input variables and their levels considered for wear study were shown in Table 2. The wear tests (wear mass loss) were carried out using face center cubic design (RSM) at random fashion shown in Table 3.

Table 2: Input Factors and their Levels for Wear Test

\begin{tabular}{|l|c|c|c|c|}
\hline \multirow{2}{*}{ Variable } & \multirow{2}{*}{ Symbol } & \multicolumn{3}{|c|}{ Levels } \\
\cline { 3 - 5 } & & $\mathbf{- 1}$ & $\mathbf{0}$ & $\mathbf{1}$ \\
\hline Load $(\mathrm{N})$ & $\mathrm{A}$ & 15 & 30 & 45 \\
\hline Sliding Speed (m/s) & $\mathrm{B}$ & 0.5 & 1 & 1.5 \\
\hline Sliding Distance (m) & $\mathrm{C}$ & 500 & 1000 & 1500 \\
\hline
\end{tabular}




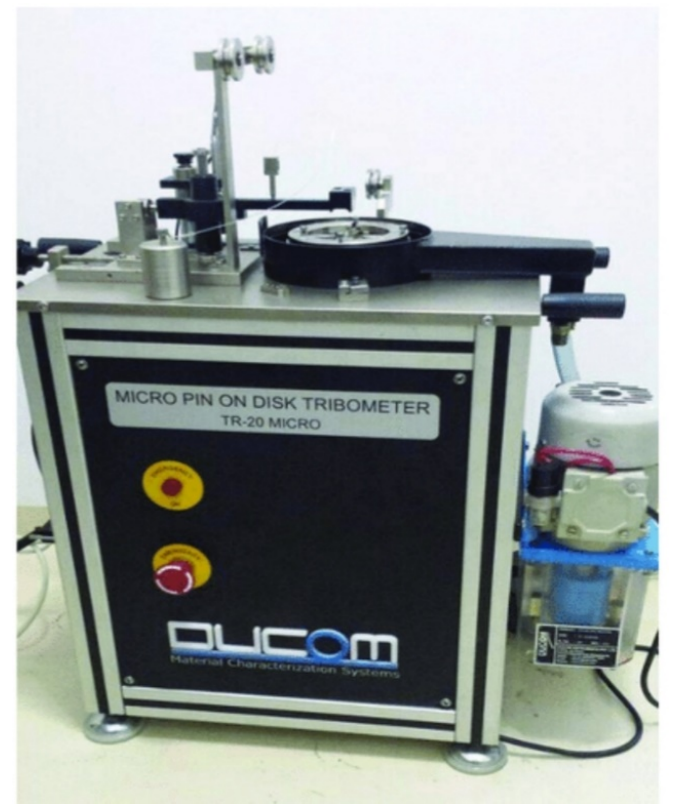

Figure 1: Pin-on-Disc Tribometer.

\section{Sliding Wear Test}

The dry sliding wear test was performed using the Pin-on - Disk triometer (DUCOM, India) according to ASTM G99 standard (Fig 1).Titanium alloy was received as hot extruded rods and the rods has machined by WEDM to required dimensions to form disc shown in Fig 2a.Fig 2b shows the coating of AlTiN on Titanium alloy. Both pin and disk were initially cleaned in acetone to remove contamination from the surface.

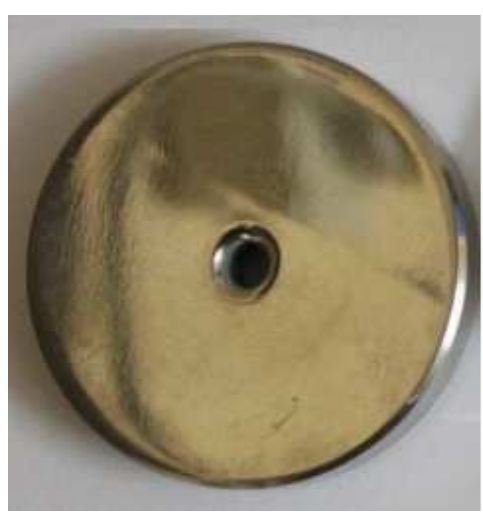

a) Uncoated

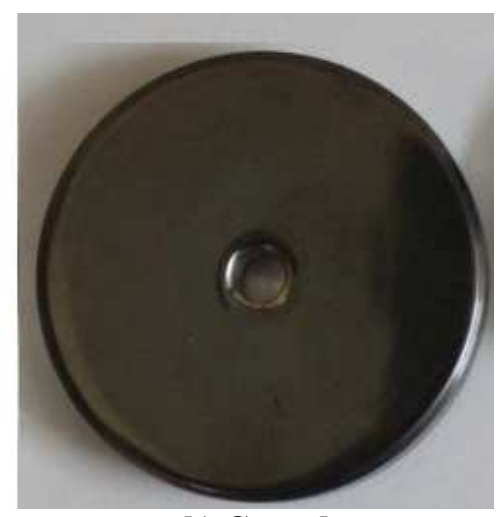

b) Coated

Figure 2: (a-b) Test Samples for Wear Test.

The test was carried out at a sliding speed of $0.5,1$ and $1.5 \mathrm{~ms}^{-1}$ and load of 15, 30 and $45 \mathrm{~N}$ and sliding distance of 500, 1000 and $1500 \mathrm{~m}$. The mass loss was calculated by analytical balance $(0.0001 \mathrm{~g}$ least count) before and after wear tests. 
Table 3: Experimental Results of Wear Test

\begin{tabular}{|c|c|c|c|c|}
\hline \multirow{2}{*}{ S No } & \multicolumn{3}{|c|}{ Input Factors } & Response \\
\cline { 2 - 5 } & $\mathbf{L o a d}$ & Sliding Speed & Sliding Distance & Wear-Mass loss \\
\cline { 2 - 5 } & $\mathbf{N}$ & $\mathbf{m} / \mathbf{s}$ & $\mathbf{m}$ & $\mathbf{m g}$ \\
\hline 1 & 30 & 1 & 1000 & 55 \\
\hline 3 & 15 & 0.5 & 500 & 24 \\
\hline 4 & 30 & 1 & 1500 & 46 \\
\hline 5 & 30 & 0.5 & 1000 & 35 \\
\hline 6 & 45 & 0.5 & 500 & 100 \\
\hline 7 & 45 & 1.5 & 1500 & 63 \\
\hline 8 & 30 & 1.5 & 1000 & 49 \\
\hline 9 & 30 & 1 & 1000 & 40 \\
\hline 10 & 15 & 1.5 & 1500 & 46 \\
\hline 11 & 30 & 1 & 1000 & 68 \\
\hline 12 & 45 & 1 & 1000 & 96 \\
\hline 13 & 45 & 0.5 & 1500 & 33 \\
\hline 14 & 15 & 0.5 & 1500 & 52 \\
\hline 15 & 30 & 1 & 1000 & 39 \\
\hline 16 & 45 & 1.5 & 500 & 26 \\
\hline 17 & 15 & 1 & 1000 & 26 \\
\hline 18 & 15 & 1.5 & 500 & 48 \\
\hline 19 & 30 & 1 & 1000 & 26 \\
\hline 20 & 30 & 1 & 500 & 50 \\
\hline
\end{tabular}

\section{RESULT AND DISCUSSIONS}

\section{Statistical Analysis}

The statistical analysis applied for analyzing the responses as per input factors combinations, coefficients estimation, and model adequacy checking and predicting the responses [26]. The factors considered for study were load, sliding speed and sliding distance. The wear mass loss was taken as response parameters. Three factors with three levels face centered cubic design (RSM) were done using Design Expert software. The experimental results of wear test of coated on titanium alloy was presented in Table [3].

\section{Mathematical Models for Wear Mass Loss}

The mathematical models for responses are estimated by given input trails. The quadratic equations are used to express the wear mass loss $\left(\mathrm{Y}_{\mathrm{WML}}\right)$ as shown in Equation (1). These developed model equations are used for predicting the wear mass loss with a coded unit as follows:

Model equation of wear mass loss:

$$
\mathrm{Y}_{\mathrm{WML}}=49.11+18.90 \times \mathrm{A}+3.10 \times \mathrm{B}+17.50 \times \mathrm{C}+12.37 \times \mathrm{AC}+7.44 \times \mathrm{B}^{2}-7.5 \times \mathrm{C}^{2}
$$

The quadratic equation for WML (Eqn. (1) shows that the main factors such as applied load, sliding speed, sliding distance; interaction term $\mathrm{AC}$ and pure quadratic term $\mathrm{B}^{2}$ and $\mathrm{C}^{2}$ has maximum influences on wear mass loss.

\section{Model Adequacy Testing}

The following graphical analysis was used for validating the adequacy of model. Figure (3) shows the residual plot for WML. The normal probability plot for the WML shows that the residuals fall in a straight line, which clearly shows the errors are normally distributed and no outliers are presented. The residuals are spread at random fashion suggesting that 
they are independent shown in the Fig-3b.There is no unusual structure from Fig-3c which confirms the model is correct. This shows the model fits well with the experimental results. The $\mathrm{R}^{2}$ and $\mathrm{R}^{2}$ (adj) values for WML are 0.9836 and 0.9761 respectively. The $\mathrm{R}^{2}$ values are good agreement with $\mathrm{R}^{2}$ (adj) values which indicates that model data fits with experimental values. In models, the both $\mathrm{R}^{2}$ and $\mathrm{R}^{2}$ (adj) values are above $95 \%$, which allows the model fit to prediction of solution.

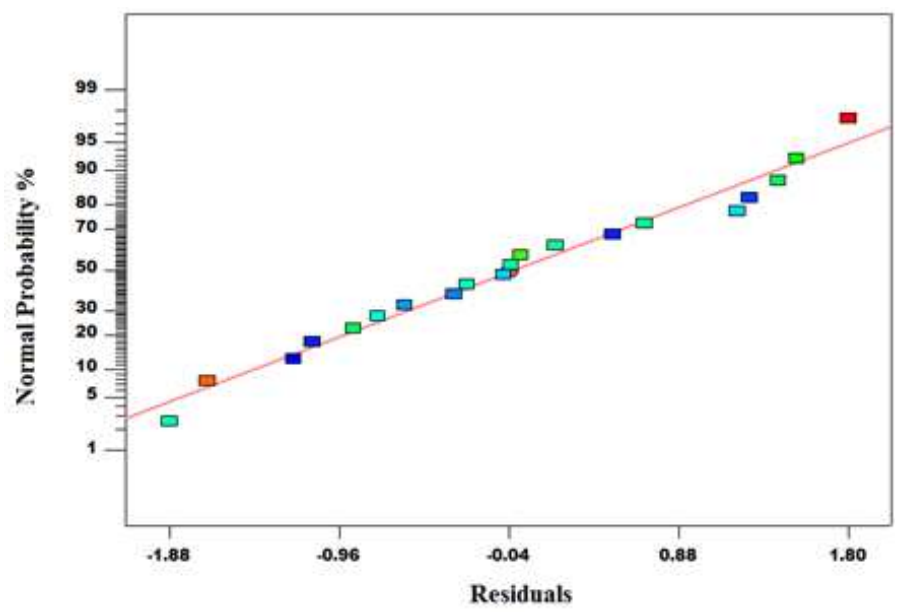

(a): Normal Probability Plot.

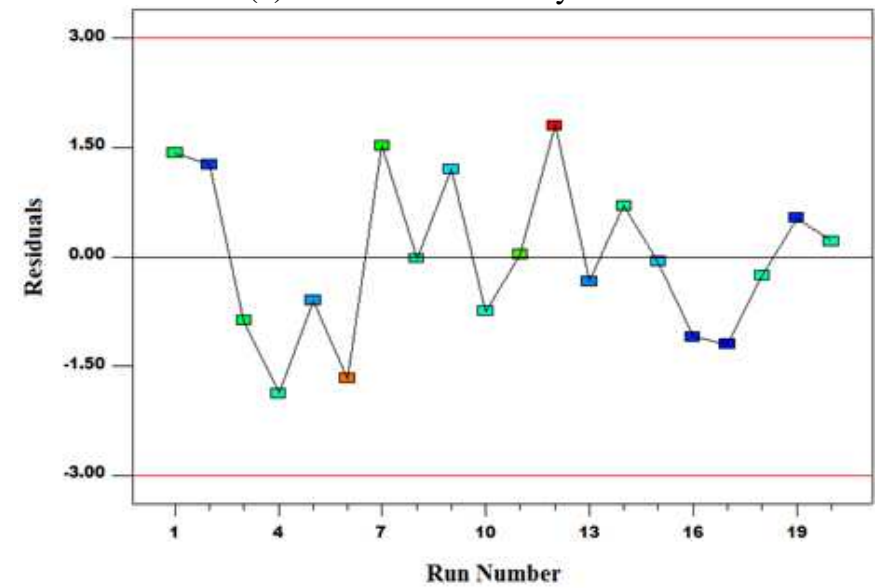

(b): Residual vs. Order of Experimentation.

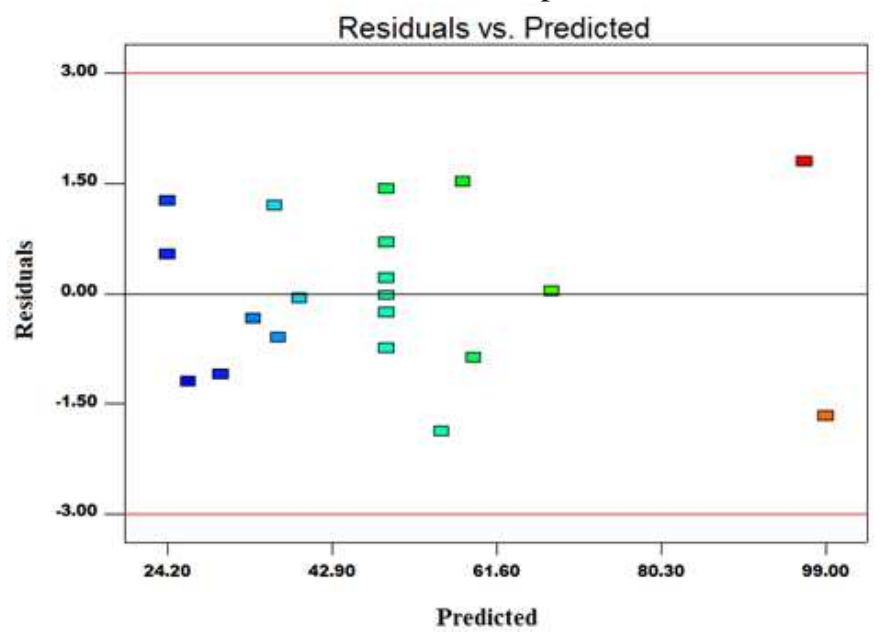

(c): Residuals vs Predicted Values.

Figures 3: [a-c] Residual Plot for WML. 


\section{Analysis of Wear Mass Loss}

The ANOVA for WML is presented in Tables 4. The model is significant for WML. The P values indicate the significance of factors, which is less than 0.05 . It shows that the model has $95 \%$ confidence interval. $\mathrm{R}^{2}$ values of WML model is 0.9836. Insignificant factors are eliminated by the backward elimination process. This indicates that developed model were adequate and the predicted values were in good agreement with the measured data. The quadratic reduced model of WML is presented in ANOVA Tables 4.

Table 4: ANOVA for Wear Mass Loss

\begin{tabular}{|l|c|c|c|c|c|c|}
\hline Source & Sum of Square & Degree of freedom & Mean Square & F Value & p-value Prob> F & \\
\hline Model & 8180.89 & 6 & 1363.8 & 130.27 & $<0.0001$ & Significant \\
\hline A & 3572.10 & 1 & 3572.10 & 340.29 & $<0.0001$ & \\
\hline B & 96.10 & 1 & 96.10 & 9.18 & 0.0097 & \\
\hline C & 3062.50 & 1 & 3062.50 & 292.50 & $<0.0001$ & \\
\hline AC & 1225.13 & 1 & 1225.13 & 117.05 & $<0.0001$ & \\
\hline$B^{2}$ & 177.01 & 1 & 177.01 & 16.91 & 0.0012 & \\
\hline$C^{2}$ & 183.01 & 1 & 183.01 & 17.49 & 0.0011 & \\
\hline Residual & 136.06 & 13 & 10.47 & & & \\
\hline Lack of Fit & 86.06 & 8 & 10.76 & 1.08 & 0.4905 & \\
\hline Pure Error & 50 & 5 & 10 & & & \\
\hline Cor Total & 8316.95 & 19 & & & & \\
\hline
\end{tabular}

In sliding wear, the load applied and the sliding distance was an important parameter than the sliding speed. From the ANOVA (Table 4) interaction of $\mathrm{A}$ and $\mathrm{C}$, quadratic effect of sliding speed and sliding distance also influences the wear mass loss. The wear mass loss gets increased while increasing the load and sliding distance shown in Fig (4a-b). The higher wear mass loss occurred at high level of load and sliding distance. From Fig. 4(a, b), it was found that the AlTiN coated surface deforms slightly at the initial applied load of $15 \mathrm{~N}$ and while increasing load and distance cause the abrasive wear leads to higher wear mass loss. The asperities get compacted between the sliding surfaces contributes to blunt surface increasing contact area cause the higher wear mass loss while increasing sliding distance. From the Fig (5ab, 6a-b) it was noticed that the sliding speed has less influences on wear mass loss.

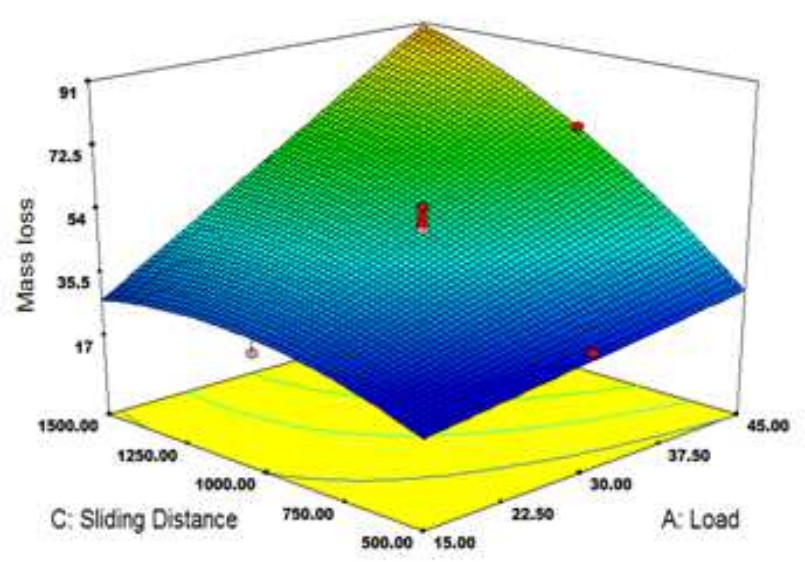

Figure 4: a. 3D-Surface plot-WML [A Vs C]

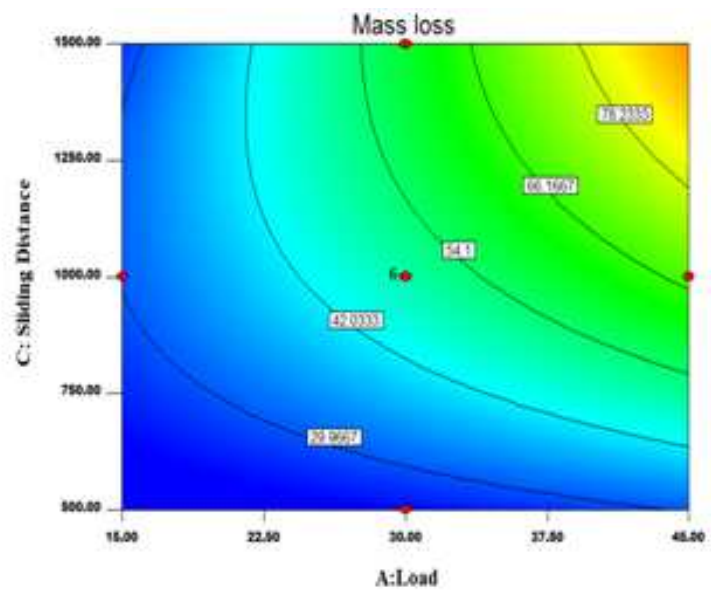

Figure 4: b. Contour plot-WML [A Vs C]. 


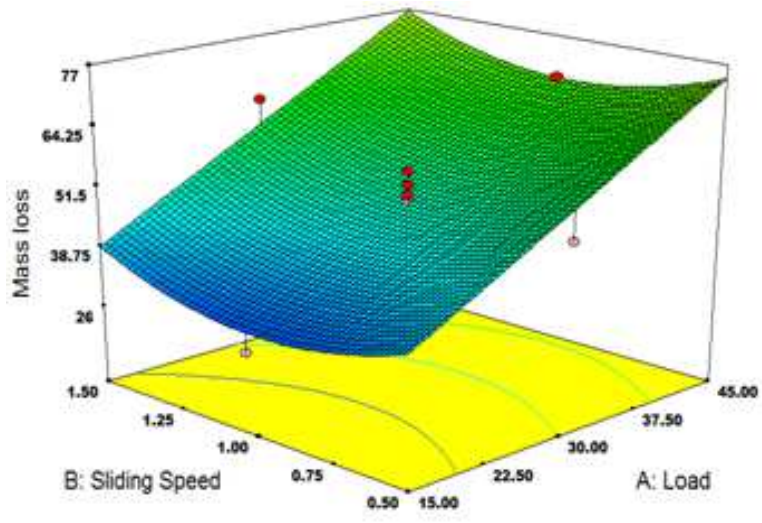

Figure 5: a. 3D-Surface plot-WML [A Vs B]

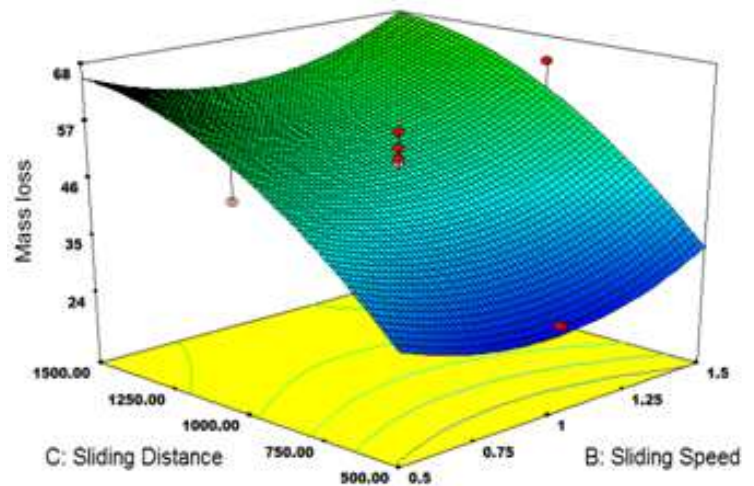

Figure 6: a. 3D-Surface plot-WML [B Vs C]

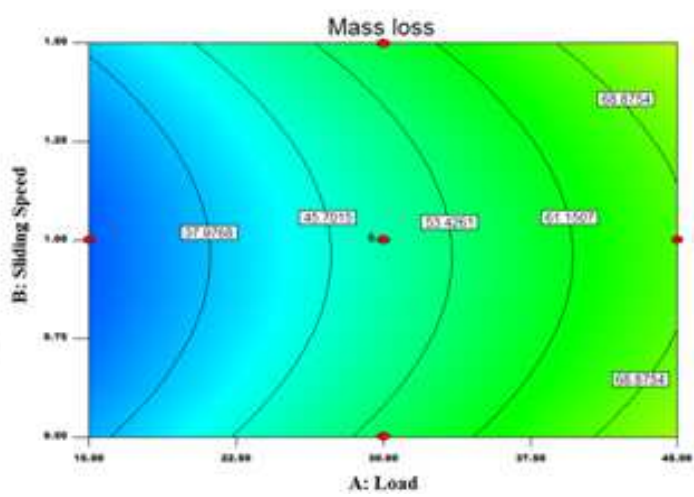

Figure 5: b. Contour plot-WML [A Vs B].

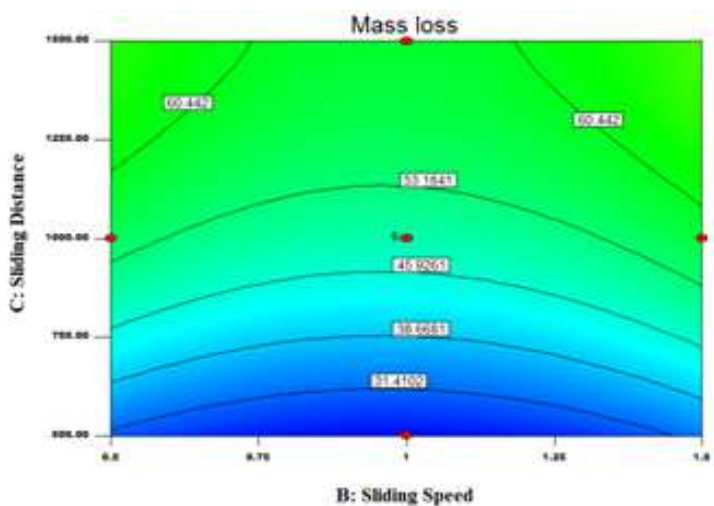

Figure 6: b. Contour plot-WML [B Vs C].

Desirability based optimization technique was employed for finding the optimal combination for wear test [26]. The objective function for wear test is minimum wear mass loss. The experimental results were validated by confirmation test which was conducted based on the optimal conditions using Design Expert software. The optimal combinations for lower wear mass loss are $15 \mathrm{~N}$ applied load, $0.5 \mathrm{~m} / \mathrm{s}$ sliding speed and $500 \mathrm{~m}$ sliding distance(Table 5) with desirability value of 0.961.It is observed that the predicted values and experimental values are in good agreement within the 95 per cent confidence intervals shown in Table 5.

Table 5: Optimum Conditions for Wear Mass Loss

\begin{tabular}{|c|c|c|c|c|c|c|c|}
\hline \multirow{2}{*}{ Response } & \multirow{2}{*}{ Goal } & \multirow{2}{*}{ Desirability } & \multicolumn{3}{|c|}{ Optimum Combination } & Predicted & $\begin{array}{c}\text { Actual } \\
\text { Value }\end{array}$ \\
\cline { 4 - 6 } & & & $\mathbf{A}(\mathbf{N})$ & $\mathbf{B}(\mathbf{m} / \mathbf{s})$ & $\mathbf{C}(\mathbf{m})$ & \\
Value
\end{tabular}

\section{CONCLUSIONS}

The sliding wear behavior of AlTiN coated on titanium alloy by physical vapor deposition process was investigated.

The statistical analysis shows that applied load (A), sliding speed (B) sliding distance (C), interaction of A and C, pure quadratic term $\mathrm{B}^{2}$ and $\mathrm{C}^{2}$ has maximum influences on wear mass loss.

The higher wear mass loss $100 \mathrm{~g}$ could be found at $45 \mathrm{~N}$ applied load, $1.5 \mathrm{~m} / \mathrm{s}$ sliding speed and $1500 \mathrm{~m}$ sliding distance.

Desirability based optimization techniques was employed. The result shows that the minimum wear mass loss has found at applied load $15 \mathrm{~N}$, sliding speed $0.5 \mathrm{~m} / \mathrm{s}$ and sliding distance $500 \mathrm{~m}$. 


\section{REFERENCES}

1. C. Leyens, M. Peters, Titanium and Titanium Alloys: Fundamentals and Applications, John Wiley \& Sons, 2003.

2. P. Sivaprakasam, P.Hariharan, S. Gowri, Analysis of Machining Parameters of $\mu$-WED Mon Titanium Alloy, International Journal of Applied Engineering Research, Vol. 9 No.26 (2014) pp. 8893-8896.

3. A. Zhecheva, W. Sha, S. Malinov, A. Long, Enhancing the microstructure and properties of titanium alloys through nitriding and other surface engineering methods, Surface Coat. Technol. 200 (7) (2005) 2192-2207.

4. M. Walczak, K. Drozd, Curr. Issues Pharm. Med.Sci.29, 158 (2016).

5. Abbas, Abeer R., Kadhim A. Hebeatir, and Kadhim K. Resan. "Effect of CO2 Laser on Some Properties of NI46TI50CU4 Shape Memory Alloy." International Journal of Mechanical and Production Engineering Research and Development 8.02 (2018): 451-460.

6. W.S.W. Harun, N.S. Manam, M.S.I.N. Kamariah,S. Sharif, A.H. Zulkifly, I. Ahmad, H. Miura, PowderTechnol. 331 , 74 (2018).

7. R. Karpinski, Ł. Jaworski, M. Szala, M. Manko, ITM Web Conf. 15, 07006 (2017).

8. M. Walczak, K. Drozd, M. Szala, J. Caban, Chiang Mai, J. Sci. 46, 766 (2019).

9. Cagan, Suleyman Cinar, and Berat Baris Buldum. "Investigation of the effect of minimum quantity lubrication (MQL) on the machining of titanium and its alloys a review." Int. J. Mech. Prod. Eng. Res. Dev. 7 (2017): 453-462.

10. Tian YS, ChenCZ, LiST, Huo QH.REFRT research progress on laser surface modification oftitaniumalloys.Appl.Surf.Sci.2005;242:177-84.

11. D. Nolan, S.W. Huang, V. Leskovsek, S. Braun, Sliding wear of titanium nitride thin films deposited on Ti-6Al-4V alloy by PVD and plasma nitriding processes, Surface Coat. Technol. 200 (20-21) (2006) 5698-5705.

12. R. Lu, H. Zhang, Y. Mitsuya, K. Fukuzawa, S. Itoh, Influence of surface roughness and coating on the friction properties of nanometer-thick liquid lubricant films, Mater.Des. S0043-1648 (2014) 00232-00234.

13. J.A.-B.Wilson, S. Banfield, J. Eichler, A. Leyland, A. Matthews, J. Housden, An investigation into the tribological performance of Physical Vapour Deposition (PVD) coating son high thermal conductivity Cu-alloy substrates and the effect of an intermediate electroless Ni-P layer prior to PVD treatment, Thin Solid Films 520(2012) 2922-2931.

14. Ahmad, M. Mustafaiz, et al. "Optimization of Process Parameters in Electric Discharge Machining Process." International Journal of Mechanical Engineering (IJME) (2016).

15. M.Z.A. Yazid, C.H. CheHaron, J.A. Ghani, G.A. Ibrahim, A.Y.M. Said, Surface integrity of Inconel 718 when finish turning with PVD coated carbide tool under MQL, Procedia Eng 19 (2011) 396-401.

16. B.D. Beake, G.S. Fox-Rabinovich, Progress in high temperature nanomechanical testing of coatings for optimizing their performance in high speed machining, Surf.Coating. Technol. 255 (2014) 102-111.

17. B.-J. Xiao et al., "Microstructure, mechanical properties and cutting performance of AlTiN coatings prepared via arc ion plating using the arc splitting technique," Surface and Coatings Technology, vol. 311, pp. 98-103, 2017/02/15/2017.

18. H.C. Barshilia, M.S. Parkash, A. Jain, K.S. Rajam, Structure, hardness and thermal stability of TiAlN and nanolayered TiAlN/CrN multilayer films, Vacuum 77 (2005) 169-179.

19. V.K. Willian Grips, H. Barshilia, V.E. Selvi, Kalavati, K.S. Ranjam, Electrochemical behavior of single layer CrN, TiN, TiAlN coatings and nanolayered TiAlN/CrN multilayer coatings prepared by reactive direct current magnetron sputtering, Thin Solid Films 514 (2006) 204-211. 
20. J.A.-B.Wilson, S. Banfield, J. Eichler, A. Leyland, A. Matthews, J. Housden, An investigation into the tribological performance of Physical Vapour Deposition (PVD) coating son high thermal conductivity Cu-alloy substrates and the effect of an intermediate electroless Ni-P layer prior to PVD treatment, Thin Solid Films 520(2012) 2922-2931.

21. Alavala, Chennakesava R. "FEM analysis of single point incremental forming process and validation with grid-based experimental deformation analysis." International Journal of Mechanical Engineering 5.5 (2016): 1-6.

22. K. Kutschej, P.H. Mayrhofer, M. Kathrein, P. Polcikd, R. Tessadrie, C. Mittereret, Structure, mechanical and tribological properties of sputtered Ti1-xAlxN coatings with $0.5 \leq x \leq 0.75$, Surf. Coat. Tech. 200 (2005) 2358-2365.

23. L. Chen, J. Paulitsch, Y. Du, P.H. Mayrhofer, Thermal stability and oxidation resistance of Ti-Al-N coatings, Surf. Coat. Tech. 206 (2012) 2954-2960.

24. J.X. Deng, A.H. Liu, Dry sliding wear behavior of PVD TiN, Ti55Al45N, and Ti35Al65N coatings at temperatures up to 600 ${ }^{\circ}$ C, Int. J. Refract. Met.Hard Mater. 41 (2013)241-249.

25. Z.P. Hao, Y.H. Fan, J.Q. Lin, Z.X. Yu, Wear characteristics and wear control method of PVD-coated carbide tool in turning Inconel 718, Int. J. Adv. Manuf. Technol. 78(2015) 1329-1336.

26. K. Dejun, G. Haoyuan, and W. Wenchang, "Effects of Loadings on Friction and Wear Behaviors of Cathodic Arc Ion Plating AlTiN Coating at High Temperature," Tribology Transactions, vol. 59, no. 4, pp. 604-612, 2016/07/03 2016.

27. M. Szala, M. Walczak, K. Pasierbiewicz, and M. Kamiński, "Cavitation Erosion and Sliding Wear Mechanisms of AlTiN and TiAlN Films Deposited on Stainless Steel Substrate," Journal of Coatings, vol. 9, no. 5, p. 340, 2019.

28. Myers, R.H. (1971) Response Surface Methodology, Vol. 4, pp.29-52, Allyn and Bacon, Inc.,Boston, MA, USA.

29. I. Saravanan, A. ElayaPerumal, S.C. Vettivel, N. Selvakumar, A. Baradeswaran, Optimizing wear behavior of TiN coated SS 316L against Ti alloy using Response SurfaceMethodology, Mater. Des. 67 (2015) 469-482.

30. P. Sivaprakasam, P.Hariharan, S. Gowri, Modeling and analysis of Micro-Wire EDM process of titanium alloy (Ti-6Al-4V) using response surface approach, Engineering Science and Technology, an International Journal, Volume 17, Issue 4, 2014, pp.227-235.

31. Sivaprakasam P, Elias G, MaheanderaPrabu P, Balasubramani P, Experimental investigations on wear properties of AlTiN coated 316LVM stainless steel, Materials Today: Proceeding, Published online: 10 June 2020. 

